\title{
SISTEM PENGENALAN BUNGA BERBASIS PENGOLAHAN CITRA DAN PENGKLASIFIKASI JARAK
}

\author{
Fitri Muwardi, Abdul Fadlil \\ Program Studi Teknik Elektro, Fakultas Teknologi Industri, Universitas Ahmad Dahlan \\ Kampus III, Jln. Prof. Dr. Soepomo, S.H. Umbulharjo, Yogyakarta 55161 \\ e-mail: muwardi95@gmail.com, fadlil3@yahoo.com
}

\begin{abstract}
Computer based recognition system is processing to generate information the flowers into the computer. Those is using reabilty and intelligency system to conduct it. In this study, handphone camera that has used the data acquisition of the flower image. Then, Its conduted image pre-processing (grayscale and cropping) and used feature extraction (color histogram and order 1 statistics) also distance classification (Manhattan and Euclidean). This research has provided of 2 steps it selected standard pattern and testing. To conduct reference of standard pattern its provide of 9 model are the alamanda flower, the kamboja flower, the kenanga flower, the lidah mertua flower, the white lili flower, the sun flower, the rose flower, the jasmine flower, and the shoes flower. In addtion, the system is used of 25 model. So that provide are 225 models for system testing. The result this identification system has shown high accuracy level of $85 \%$ by Manhattan distance method with histogram feature extraction also the lowest accuracy rate of $77 \%$ using Eucludean classification method with the 1st orde of statistics feature extraction
\end{abstract}

Keywords: introduction of flowers; distance method; manhattan and euclidean.

\begin{abstract}
Abstrak
Sistem pengenalan jenis bunga berbasis komputer merupakan proses memasukkan informasi berupa citra jenis bunga ke dalam komputer. Perlu adanya sistem yang handal dan cerdas untuk melaksanakan tugas tersebut. Pada penelitian ini kamera handphone dimanfaatkan untuk akuisisi data citra jenis bunga. Selanjutnya dilakukan pre-processing (grayscale dan cropping) terhadap citra, untuk ektraksi ciri (histogram warna citra dan statistik orde 1), dan pengklasifikasi jarak (manhattan dan Euclidean). Pada penelitian ini dilakukan melalui 2 tahap yaitu penentuan pola standar dan pengujian. Data yang digunakan sebagai pola standar referensi sebanyak 9 sampel untuk masing-masing jenis bunga yaitu bunga alamanda, bunga kamboja, bunga kenanga, bunga lidah mertua, bunga lili putih, bunga matahari, bunga mawar, bunga melati, bunga sepatu. Sedangkan untuk pengujian uji kerja sistem menggunakan 25 sampel untuk setiap masing-masing jenis bunga jadi total citra uji 225 sampel. Hasil pengujian sistem identifikasi citra jenis bunga menunjukkan tingkat akurasi yang tinggi sebesar $85 \%$ dengan menggunakan metode jarak manhattan dengan ektraksi ciri histogram, dan paling rendah tingkat akurasinya adalah 77\%, menggunakan metode klasifikasi Euclidean dengan ektraksi ciri statistik orde 1.
\end{abstract}

Kata Kunci: pengenalan bunga; metode jarak; manhattan dan euclidean.

\section{Pendahuluan}

Perkembangan teknologi pengolahan citra (image processing) sekarang ini menyediakan kemungkinan manusia untuk membuat suatu sistem yang dapat mengenali suatu citra digital. Pengolahan citra merupakan salah satu jenis teknologi untuk menyelesaikan masalah mengenai pemrosesan gambar. Dalam pengolahan citra, gambar diolah sedemikian rupa sehingga gambar tersebut dapat digunakan untuk aplikasi lebih lanjut. 
Bunga merupakan modifikasi suatu tunas (batang dan daun) yang bentuk, warna, dan susunannya disesuaikan dengan kepentingan tumbuhan. Oleh karena itu, bunga ini berfungsi sebagai tempat berlangsungnya penyerbukan dan pembuahan yang akhirnya dapat dihasilkan alat-alat perkembangbiakan. Mengingat pentingnya bunga bagi tumbuhan maka pada bunga terdapat sifat-sifat yang merupakan penyesuaian untuk melaksanakan fungsinya sebagai penghasil alat perkembangbiakan, pada umumnya bunga mempunyai warna menarik, berbau harum, bentuknya bermacam-macam, dan biasanya mengandung madu.Teknologi komputer saat ini terus mengalami perkembangan yang sangat pesat tarutama yang berbasis teknologi multimedia atau digital.

Teknologi komputer yang mampu menghasilkan informasi dengan tampilan yang lebih menarik. Sistem pengenalan bunga menggunakan citra digital sebagai input yang akan diproses dan diidentifikasi bukanlah perkara mudah. Bunga mempunyai jenis yang sangat bervariasi. Ekstraksi ciri bertujuan untuk menajamkan perbedaan-perbedaan pola, sehingga akan mudah dalam pemisahan kategori kelas pada proseklasifikasi. Terdapat bermacam-macam fitur dalam melakukan ekstraksi ciri yaitu amplitude, histrogram, matriks coocurence, gradient, deteksi tepi, spectrum fourier, wavelet, fractal dan lain-lain.

Banyak metode yang dapat digunakan dalam melakukan proses identifikasi klasifikasi terhadap citra bunga yaitu metode manhattan, euclidean, minkowski, city blok distance, chebysev, one minus correlation coeficient dan lain-lain. Dalam penelitian ini, penulis akan menggunakan metode manhattan dan euclidean karena dari kajian terdahulu belum ada yang menggunakan campuran kedua metode tersebut. Untuk mendukung penelitian ini, banyak aplikasi komputer yang dapat digunakan untuk pengolahan citra digital yaitu MATLAB, Visual Basic, pemrograman DELPHI. Pada penelitian ini penulis akan menggunakan aplikasi MATLAB (matrix laboratory) dengan menggunakan fasilitas GUI (graphic user interface) untuk mendukung dalam pengolahan citra digital. Citra dapat disimpan di dalam berkas (file) dalam berbagai format yaitu: bmp, .jpg, .png, .gif dan lain sebagainya. Pada penelitian kali ini, citra yang dimasukkan menggunakan citra dengan format JPG (.jpg) dan citra selanjutnya akan dikonversi dari format rgb (red green blue) ke bentuk aras keabuan grey level sehingga memudahkan dalam melakukan identifikasi citra [1].

\section{Metode Penelitian}

\subsection{Dasar Teori}

\subsubsection{Bunga}

Bunga merupakan modifikasi suatu tunas (batang dan daun) yang bentuk, warna, dan susunannya disesuaikan dengan kepentingan tumbuhan. Oleh karena itu, bunga ini berfungsi sebagai tempat berlangsungnya penyerbukan dan pembuahan yang akhirnya dapat dihasilkan alat-alat perkembangbiakan. Mengingat pentingnya bunga bagi tumbuhan maka pada bunga terdapat sifat-sifat yang merupakan penyesuaian untuk melaksanakan fungsinya sebagai penghasil alat perkembangbiakan, pada umumnya bunga mempunyai warna menarik, berbau harum, bentuknya bermacam-macam dan biasanya mengandung madu. Pada penelitian kali ini penulis akan menggunakan obyek berbagai jenis bunga (alamanda, kamboja, kenanga, lidah mertua, lili putih, matahari, mawar, melati, sepatu).

\subsubsection{Pengolah Citra}

Pengolahan citra merupakan bidang yang bersifat multidisiplin, yang terdiri dari banyak aspek, antara lain: fisika (optik, nuklir, gelombang, dll), elektronika, matematika, seni, fotografi, dan teknologi komputer. Pengolahan citra (image processing) memiliki hubungan yang sangat erat dengan disiplin ilmu yang jika sebuah disiplin ilmu dinyatakan dalam bentuk proses suatu input menjadikan output, maka pengolahan citra memiliki input berpupa citra serta output berupa citra [2].

\subsubsection{Model Warna RGB}

RGB adalah suatu model warna yang terdiri atas 3 buah warna yaitu merah (red), hijau (green), biru (blue) yang ditambahkan dengan berbagai cara untuk menghsilkan bermacammacam warna. Merubah citra RGB menjadi grayscale adalah salah satu contoh proses pengolahan citra menggunakan operasi titik. Untuk mengubah citra RGB menjadi grayscalel adalah dengan menghitung rata-rata nilai intensitas RGB dari setiap piksel penyusun citra tersebut. llustrasi nilai citra berwarna ditunjukkan dengan matrik beikut [3]: 


$$
\begin{aligned}
& I_{\text {red }}(m, n, 1)=\left[\begin{array}{cccc}
r_{11} & r_{12} & \cdots & r_{1 n} \\
r_{21} & r_{22} & \cdots & r_{2 n} \\
\vdots & \vdots & \ddots & \vdots \\
r_{m 1} r_{m 2} & \cdots & r_{m n}
\end{array}\right] \\
& I_{\text {green }}(m, n, 1)=\left[\begin{array}{cccc}
g_{11} & g_{12} & \cdots & g_{1 n} \\
g_{21} & g_{22} & \cdots & g_{2 n} \\
\vdots & \vdots & \ddots & \vdots \\
g_{m 1} & g_{m 2} & \cdots & g_{m n}
\end{array}\right] \\
& I_{\text {blue }}(m, n, 1)=\left[\begin{array}{cccc}
b_{11} & b_{12} & \cdots & b_{1 n} \\
b_{21} & b_{22} & \cdots & b_{2 n} \\
\vdots & \vdots & \ddots & \vdots \\
b_{m 1} & b_{m 2} & \cdots & b_{m n}
\end{array}\right]
\end{aligned}
$$

Rumus matematis yang digunakan sebagai berikut:

$$
\begin{array}{ll}
f_{g}(x, y)=\frac{f_{l}^{R}(x, y)+f_{l}^{g}(x, y)+f_{l}^{b}(x, y)}{3} & \\
\text { dimana: } \quad f_{g}(x, y) & =\text { nilai citra grayscale } \\
f_{l}^{R}(x, y) & =\text { nilai elemen citra warna merah } \\
f_{l}^{g}(x, y) & =\text { nilai elemen citra warna hijau } \\
f_{l}^{b}(x, y) & =\text { nilai elemen citra warna biru }
\end{array}
$$

\subsubsection{Citra Grayscale}

Citra skala keabuan memberi kemungkinan warna yang lebih banyak dari pada citra biner, karena ada nilai-nilai diantara nilai minimum (biasanya=0) dan nilai maksimumnya. Banyaknya kemungkinan nilai dan nilai maksimumnya bergantung pada jumlah bit yang digunakan. Pada citra grayscale ini, format citra disebut skala keabuan karena pada umumnya warna yang dipakai adalah warna hitam sebagai warna minimal dan warna putih sebagai warna minimalnya, sehingga warna antaranya adalah abu-abu [4].

\subsubsection{Cropping}

Cropping adalah proses pemotongan citra pada koordinat tertentu pada area citra. Untuk memotong bagian dari citra digunakan dua koordinat, yaitu koordinat awal yang merupakan awal koordinat bagi citra hasil pemotongan dan koordinat akhir yang merupakan titik koordinat akhir dari citra hasil pemotongan. Sehingga akan membentuk bangun segi empat yang mana tiap-tiap piksel yang ada pada area koordinat tertentu akan disimpan dalam citra yang baru.

\subsubsection{Ektraksi Ciri}

Ekstraksi ciri merupakan bagian penting dari nalisa citra. Citra adalah karakteristik untuk dari suatu obyek. Analisis bentuk merupakan salah satu metode pemisah ciri. Karakteristik ciri yang baik kurang lebih memenuhi persyaratan berikut [5].

\subsubsection{Histogram}

Histogram adalah fungsi transformasi intensitas didasarkan pada informasi yang diektrak dari citra berupa histogram. Histogram memegang peran yang sangat penting dalam pengolahan citra seperti enhanement, compression, segmentation dan description [6].

\subsubsection{Statistik Orde 1}

Orde 1 digunakan untuk membedakan tekstur ciri atau statistik atau obyek lainnya dapat menggunakan ciri statistik orde 1 atau ciri statistik orde dua. Ciri statistik orde 1 didasarkan pada karakteristik histogram citra. Ciri statistik orde 1 umumnya digunakan untuk membedakan tekstur makrostruktur (perulangan pola lokal secara periodik). Ciri statistik orde 1 antara lain: mean, variance, skewness, kurtosis dan entropy [7]. 


\subsubsection{Klasifikasi}

Menurut kamus besar bahasa indonesia klasifikasi adalah penyusunan bersistem dalam kelompok atau golongan menurut kaidah atau standar yang ditetapkan. Sedangkan pengertian secara umum klasifikasi adalah suatu kegiatan yang mengelompokkan benda yang memiliki beberapa ciri yang sama dan memisahkan benda yang tidak sama [8].

\subsection{Alat dan Bahan Penelitian}

\subsubsection{Alat Penelitian}

Alat yang digunakan untuk penelitian ini adalah perangkat lunak (software) dan perangkat keras (hardware). Perangkat lunak yang dibutuhkan meliputi sistem operasi dan perangkat lunak aplikasi yang lain, dan camera HP. Kebutuhan perangkat keras meliputi seperangkat komputer. Laptop lenovo core i3 tipe prosesor. Intel core i3 processor, processor onboard: Inte/ core $^{\mathrm{TM}}$ i3$3110 \mathrm{M}$ processor $(2.4 \mathrm{GHz}$, cache $3 \mathrm{MB})$, chipset: Inte周 HM77, memori standar: 2 GB DDR3, kapasitas penyimpanan: 500 GB serial ATA 5400 RPM, tipe grafis: NVIDIA geforce 705M 1GB, ukuran layar : 14" WXGA LED, wireless network protocol: IEEE 802.11b, IEEE 802.11g, IEEE 802.11n, kamera HP, kamera utama: 13 MP, 4160 X 3120 pixels, kamera depan: 5 MP, aperture F/2.0, video record 1080p@30fps, $85^{\circ}$ wide viewing angle

\subsubsection{Bahan Penelitian}

Subyek penelitian ini adalah membuat sistem identifikasi jenis bunga berbasis pengolahan citra dan pengklasifikasi jarak menggunakan metode klasifikasi dan euclidean. data yang dipakai dalam penelitian ini menggunakan 9 jenis data jenis bunga yaitu bunga alamda, kamboja, kenanga, lidah mertua, sepatu, mawar, melati, matahari, lili putih yang berupa file citra yang berektensi JPG (Join photographics Group). Identifikasi citra jenis bunga dilakukan dengan menggunakan citra yang terpisah didalam file komputer. Jika sistem menangkap citra jenis bunga. Obyek yang telah dilatihkan, maka sistem akan dalam mengidentifikasinya [9].

\subsection{Perancangan Sistem}

Pemrosesan awal adalah proses untuk mendapatkan informasi citra jenis bunga dengan mengkonversi citra asli menjadi citra grayscale dan memisahkan citra dari background dengan cara cropping.

\subsubsection{Diagram Sistem Identifikasi Jenis Bunga}

Diagram sistem identifikasi jenis bunga dapat dilihat pada Gambar 1.

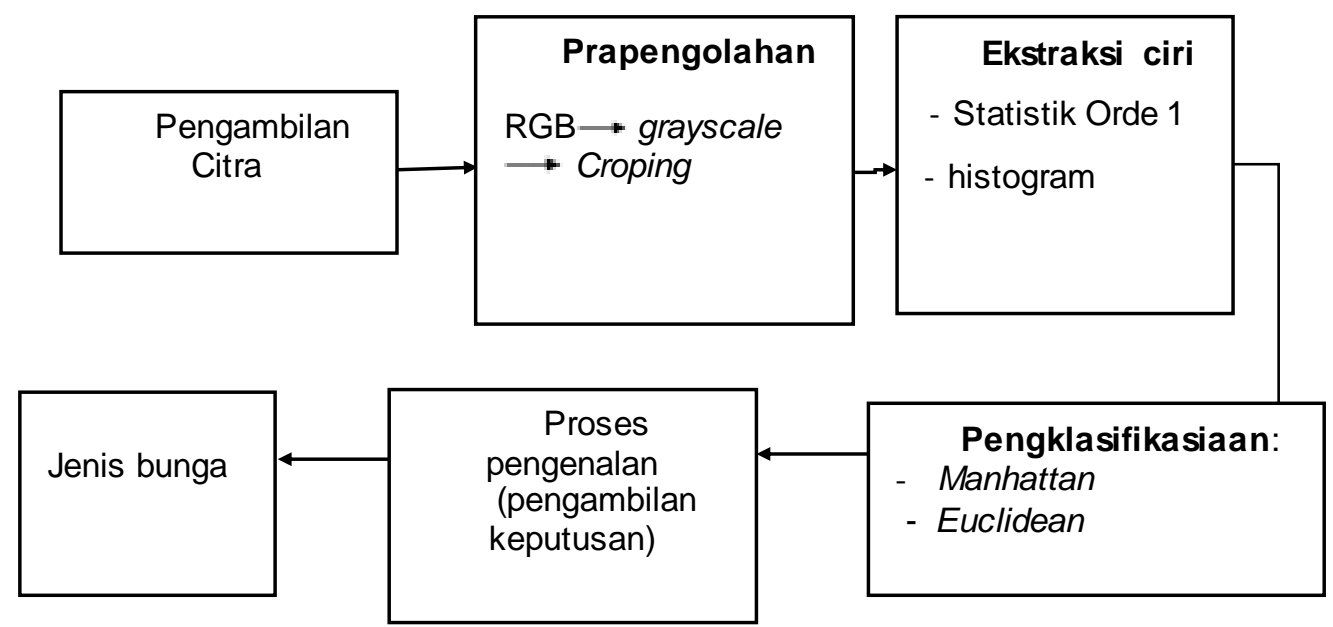

Gambar 1. Diagram sistem identifikasi jenis bunga

Hal-hal yang harus dipertimbangkan dalam sistem identifikasi citra jenis bunga adalah gambaran untuk membagi tugas-tugas dalam beberapa bagian. Masing-masing bagian harus lengkap tugasnya sebelum berpindah pada proses selanjutnya [9]. 


\subsubsection{Diagram blok Sistem Pengenalan Bunga}

Diagram yang ditunjukan pada Gambar 2 merupakan tahapan proses sistem penentuan pengenalan jenis bunga menggunakan metode jarak.

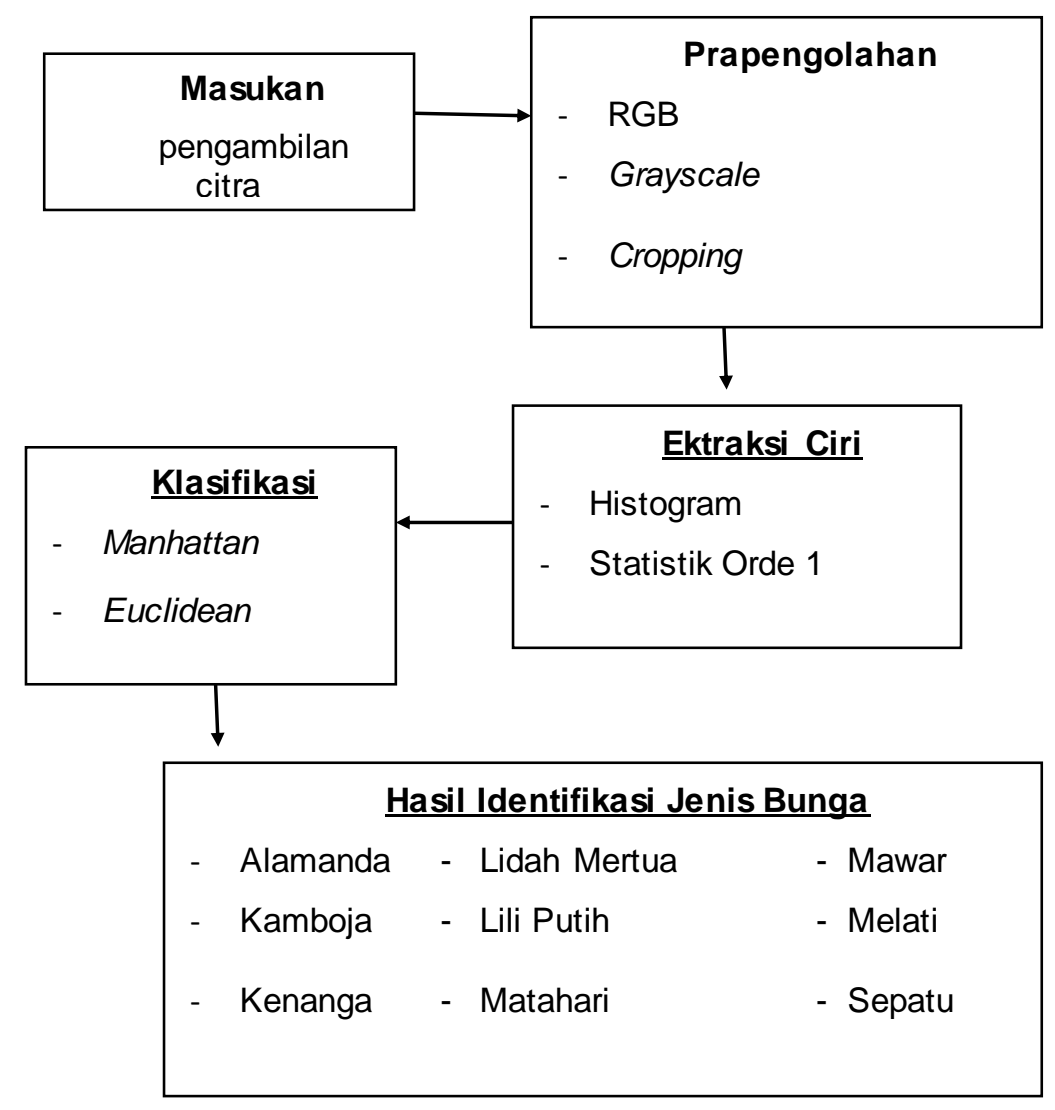

Gambar 2. Diagram blok sistem pengenalan bunga

Keterangan dari blok diagram pengenalan jenis bunga pada gambar 2 diatas adalah Input pengambilan citra jenis bunga menggunakan kamera smartphone. Pre-Procesing mengolah citra dari RGB menjadi grayscale dan cropping. Ektraksi ciri tahap memilih histogram dan statistik orde 1. Selanjutnya klasifikasi jarak memilih manhattan dan euclidan. Setelah melalui proses ektraksi ciri dan klasifikasi jarak kemudian didapatkan hasil identifikasi jenis bunga.

\section{Hasil dan Pembahasan}

Pada dasarnya sistem identifikasi jenis bunga dapat diuji setelah sistem tersebut dilatihkan terlebih dahulu. Pengujian sistem dilakukan dengan cra memasukkan citra (image) baru yang belum dikenali atau citra lain yang belum pernah dipakai pada citra pelatih (training). Pada sistem pengenalan jenis bunga basis data (database) yang digunakan dibagi menjadi dua bagian, yaitu:

1. Data citra pelatihan digunakan untuk sistem belajar atau mengenal tentang citra yang diberikan agar sistem mempunyai pengetahuan.

2. Data citra pengujian digunakan untuk mengetahui cara kerja sistem dalam mengidentifikasi citra jenis bunga.

\subsection{Hasil Pengujian Sistem Ektraksi Ciri Statistik Orde 1}

Tampilan hasil pengujian sistem pengenalan bunga menggunakan ektraksi ciri statistik orde 1 dan histogram terlihat pada Gambar 3. 


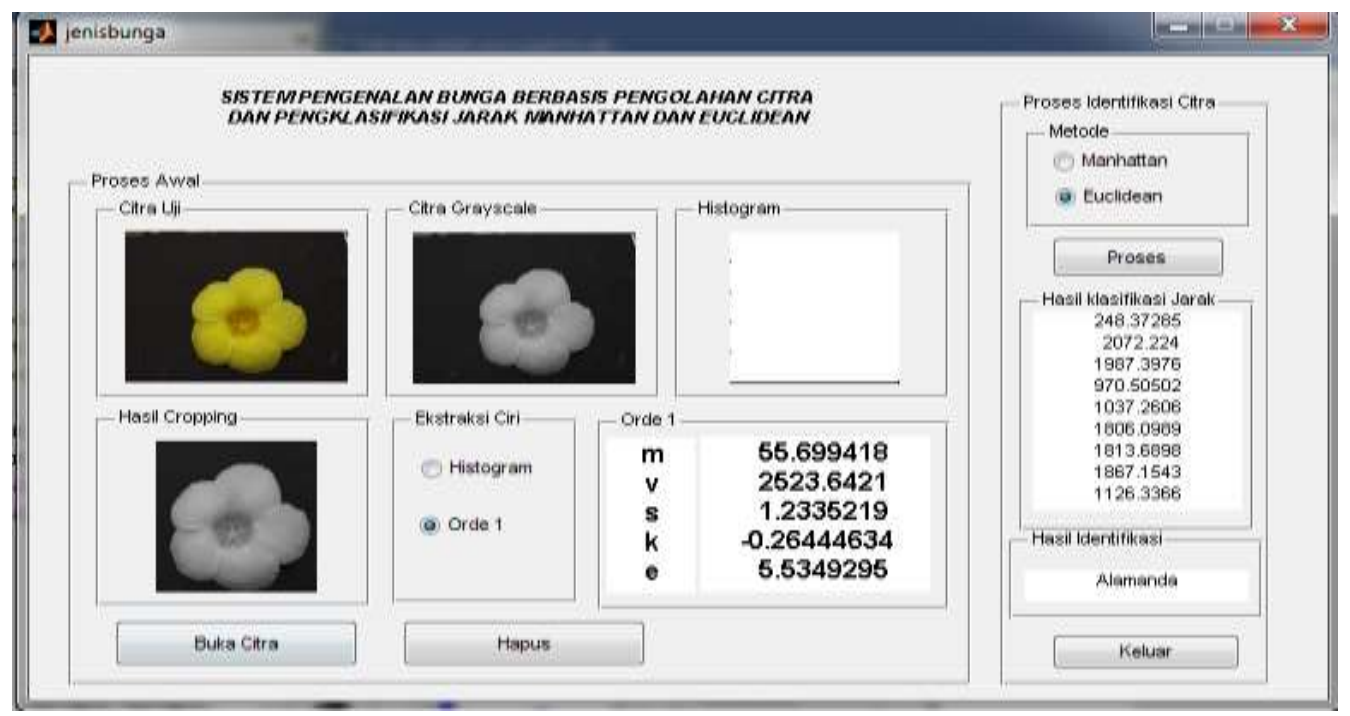

Gambar 3. Tampilan pengujian menggunakan statistik orde 1

Sistem pengenalan citra jenis bunga telah dirancang menggunakan GUI agar memudahkan bagian penggunaan. Pengujian sistem dilakukan dengan menjalankan program utama.

\subsection{Hasil Pengujian Ektraksi Ciri Histogram}

Tampilan hasil pengujian sistem pengenalan bunga menggunakan ektraksi ciri statistik orde 1 dan histogram terlihat pada Gambar 4

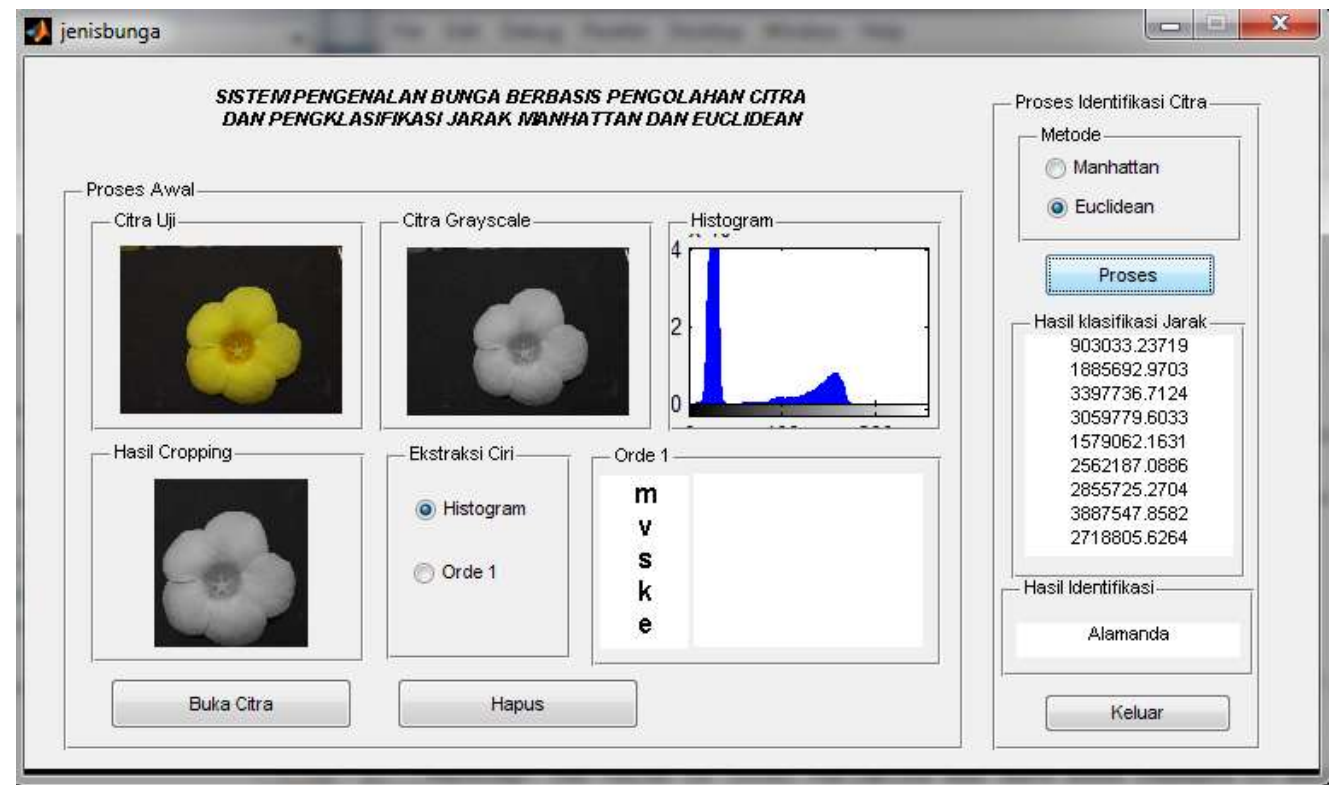

Gambar 4. Tampilan pengujian ektraksi ciri histogram dengan metode jarak euclidean

Pada Gambar 4 proses pengujian pengambilan 9 citra jenis bunga dilakukan dengan memasukkan citra bunga yang telah disimpan didalam database komputer. Proses memasukkan citra bunga ini dilakukan dengan menekan tombol "Ambil Gambar" yang hasilnya ditampilkan pada axesl. 


\subsection{Hasil Perbandingan Sistem}

Hasil perhitungan akurasi citra jenis bunga terlihat pada Tabel 1

Tabel 1. Hasil perhitungan akurasi

\begin{tabular}{ccc}
\hline Metode & Ektraksi ciri & Akurasi (\%) \\
\hline Manhattan & & 80 \\
Euclidean & Statistik orde 1 & 77 \\
Manhattan & & 85 \\
Euclidean & Histogram & 81 \\
\hline
\end{tabular}

Pada Tabel 1 merupakan Hasil penelitian atau pengujian, dapat diketahui bahwa system identifkasi citra jenis bunga menunjukkan tingkat akurasi yang paling tinggi adalah $85 \%$ dengan menggunakan metode klasifikasi jarak histogram manhattan dan ektraksi ciri histogram. Dan hasil pengujian sitem identifikasi citra jenis bunga menunjukkan tingkat akurasi yang terendah tingkat akurasinya adalah $77 \%$ dengan menggunakan metode klasifikasi jarak orde 1 euclidean. Namun untuk lebih meningkatkan uji kerja sistem masih perlu dilakukan untuk mendapatkan akurasi yang maksimal, misalnya mencoba meningkatkan kualitas citra uji dan mencoba menggunakan teknik-teknik lain pada tahap proses awal, ektraksi ciri maupun pengklasifikasinya.

\section{Kesimpulan}

Dalam pengambilan citra, cahaya ruangan dapat mempengaruhi kualitas hasil citra itu, Dalam penelitian ini ektraksi ciri yang lebih akurat dengan menggunakan ektraksi ciri histogram manhattan yaitu ektraksi ciri dari segi warna citra, Dalam sistem pengenalan bunga, metode klasifikasi jarak manhattan dan euclidean yang lebih akurat dalam mengklasifikasi citra jenis bunga adalah metode manhattan, hasil pengujian dapat diketahui bahwa sistem identifikasi citra jenis bunga menunjukkan tingkat akurasi yang tertinggi adalah $85 \%$ dengan menggunakan metode jarak manhattan dengan ektraksi ciri histogram. Sedangkan tingkat akurasi yang paling rendah adalah $77 \%$ dengan menggunakan metode jarak euclidean dengan ektraksi ciri statistik orde 1.

\section{Referensi}

[1] Marzuki Khalid, et. al, Design of an intelligent wood species recognition system, International Journal of Simulation, Systems, Science and Technology (IJSSST). 2008.

[2] Informatika. (2013). Operasi Cropping. Diperoleh dari: http://informatika.web.id/operasicropping.html. (Diakses pada 29 Juli 2017).

[3] Agus Purwo Handoko, Yustina Retno Wahyu Utami, 2009. Pengenalan BuahBerdasarkan Karakteristik Warna Citra. CSRID 1, 114-120

[4] Agus Prijono, Marvin Ch. Wijaya, 2007, Pengolahan Citra Digital MenggunakanMatlab, Cetakan Pertama, Informatika, Bandung.

[5] Nugroho, H.W. (2011). Identifikasi Citra Kacang Menggunakan Metode Metrik Jarak Manhattan dan Euclidean. Skripsi tidak dipublikasikan. Yogyakarta: Universitas Ahmad Dahlan.

[6] Sari, S.P. (2012). Sistem Identifikasi Citra Jenis Kunyit (Curcuma Domestica Val.)Menggunakan Metode Klasifikasi Minkowski Distance Family. Skripsi tidak dipublikasikan. Yogyakarta: Universitas Ahmad Dahlan.

[7] Shinta nur desmia sari, Sistem Identifikasi Citra Jahe (Zingiber officinale) Menggunakan metode jarak Czekanowski Yogyakarta: Program Studi informatika UAD. 2013

[8] Fadlil, A.(2012).Sistem Pengenalan Citra jenis-jenis Tekstil. Spektrum industri. (volume 10, nNomor 1): 24

[9] Achmad, B. \& Firdausy, K. (2005). Pengolahan Citra Digital menggunakan DELPHI. Yogyakarta: Ardi Publishing.

[10] Fadllil, A.(2016). Petunjuk Praktikkum Teknik Pengenalan pola. Universitas Ahmad Dahlan. Yogyakarta.

[11] Anggraeni, N.T. (2012). Sistem Identifikasi Citra Cabai(Campsium annum L) Menggunakan Metode Klasifikasi Citi Block Distance. Sekripsi tidak dipublikasikan. Yogyakarta: Universitas Ahmad Dahlan. 
Jurnal IImu Teknik Elektro Komputer dan Informatika (JITEKI)

Vol. 3, No. 2, Desember 2017

- 131

[12] Sugihartini, N.,Setianto, A.B., \& Efiana, N.A. (2013). Formulasi Dan Teknologi Sediaan Padat. Yogyakarta: Laboratorium Teknologi Farmasi Universitas Ahmad Dahlan. 